WellBeing International

WBI Studies Repository

$12-1988$

\title{
Bunk attendance of feedlot cattle monitored with radio frequency technology
}

D. J. Gibb

Agriculture and Agri-Food Canada

T. A. McAlllister

Agriculture and Agri-Food Canada

C. Huisma

GrowSafe Systems, Ltd.

R. D. Wiedmeier

Utah State University

Follow this and additional works at: https://www.wellbeingintlstudiesrepository.org/mmfarm

Part of the Agribusiness Commons, and the Animal Studies Commons

\section{Recommended Citation}

Gibb, D. J., McAllister, T. A., Huisma, C. and Wiedmeier, R. D. 1998. Bunk attendance of feedlot cattle monitored with radio frequency technology. Can. J. Anim. Sci. 78: 707-710. DOI: https://doi.org/10.1139/ cjas-2015-0193

This material is brought to you for free and open access by WellBeing International. It has been accepted for inclusion by an authorized administrator of the WBI Studies Repository. For more information, please contact wbisr-info@wellbeingintl.org.

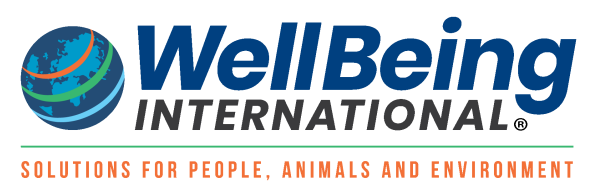




\title{
Bunk attendance of feedlot cattle monitored with radio frequency technology
}

\author{
D. J. Gibb ${ }^{1}$, T. A. McAllister ${ }^{1,2}$, C. Huisma ${ }^{3}$, and R. D. Wiedmeier ${ }^{4}$ \\ ${ }^{1}$ Research Centre, Agriculture and Agri-Food Canada, P. O. Box 3000, Lethbridge, Alberta, Canada T1J 4B1; \\ ${ }^{3}$ GrowSafe Systems Ltd., Airdrie, Alberta, Canada T4B 2A3; ${ }^{4}$ Department of Animal, Dairy and Veterinary \\ Science, Utah State University, Logan UT 84322-4815. LRC Contribution no. 3879801, received 27 March 1998, \\ accepted 28 October 1998.
}

\begin{abstract}
Gibb, D. J., McAllister, T. A., Huisma, C. and Wiedmeier, R. D. 1998. Bunk attendance of feedlot cattle monitored with radio frequency technology. Can. J. Anim. Sci. 78: 707-710. Bunk attendance of 72 feedlot cattle (412 $\pm 23.6 \mathrm{~kg})$ was monitored for $86 \mathrm{~d}$ using radio frequency technology. Late morning and late afternoon were confirmed as primary ad libitum feeding periods. The system detected differences $(P<0.005)$ in feeding behaviour in response to level of feeding and frequency of meals.
\end{abstract}

Key words: Feeding behaviour, limit feeding, feeding frequency

Gibb, D. J., McAllister, T. A., Huisma, C. et Wiedmeier, R. D. 1998. La présence à la mangeoire de bovins de boucherie a été mesureé en utilisant la technologie de fréquence radio. Can. J. Anim. Sci. 78: 707-710. La présence à la mangeoire de 72 bovins de boucherie en parc d'engraissement $(412 \pm 23.6 \mathrm{~kg})$ a été mesureé durant 86 jours en utilisant la technologie de fréquence radio. Tard le matin et tard l'après-midi ont été confirmés comme étant les principales périodes d'alimentation ad libitum. Le système a détecté des différences $(P<0.05)$ dans le comportement d'alimentation en réponse au niveau d'alimentation et à la fréquence de repas.

Mots clés: Comportement d'alimentation, limite d'alimentation, fréquence d'alimentation

Subclinical acidosis resulting from ruminal digestion of high-energy rations can compromise performance of feedlot cattle. Due to the rapid rate of digestion of starch in barley, subclinical acidosis may be costly in Canadian feedlots where barley is the predominant grain fed. For example, if it is assumed that subclinical acidosis causes an average reduction in feed efficiency of 3\%, alleviation of the disease would represent a return of $\$ 6$ to 8 per animal in Alberta. Variation in intake is an obvious symptom of acidosis in individually fed cattle but can be undetectable when intakes are averaged for a pen (Larson et al. 1992). The attempt to maintain maximal and stable intake by feedlot cattle is often referred to as "bunk management".

Feeding strategies recommended in bunk management programs are often based on intuition derived from observations of pen-fed cattle. Despite the emphasis placed on bunk management and the millions of cattle fed in North America, surprisingly little is known about feeding patterns of individual animals in a pen. Although feeding patterns of individual animals can be monitored using calan gates, pin pointers or other devices in experimental environments (Cole 1995), monitoring these patterns in a feedlot setting requires visual surveillance. Because of time constraints, visual observations are typically intermittent and infrequent. Understanding individual feeding behaviour in feedlot cattle may assist researchers in developing bunk management pro-

\footnotetext{
${ }^{2}$ To whom correspondence should be addressed.
}

grams that reduce the incidence of subacute acidosis and other digestive disturbances.

Radio frequency (RF) technology enables continuous monitoring of feed bunk attendance by individual animals in a pen. The GrowSafe system (GrowSafe Systems Ltd., Airdrie, AB) consists of an antenna that radiates a $134.2-\mathrm{kHz}$ electromagnetic field lying flush against the outer wall of the feed bunk, and transponders (Texas Instruments Incorporated, Dallas, TX) encased in plastic ear tags (Allflex USA, Dallas-Ft.Worth, TX). When eartagged cattle come within $50.4 \mathrm{~cm}$ of the antenna (i.e., when they place their heads into the feed bunk), energy from the electromagnetic field is collected and stored in a small capacitor within the transponder. Once sufficient energy is collected $(25 \mathrm{~ms})$, animal identification is transmitted back to the antenna and relayed to the computer every $6 \mathrm{~s}$ as long as the transponder remains in the electromagnetic field (Fig. 1). The reader panel is able to read multiple transponders simultaneously and differentiates among them, allowing all animals at the bunk to be detected at the same time. The bunk attendance system has been installed in four pens in the research feedlot at the Lethbridge Research Centre and validated against video surveillance data (Schwartzkopf-Genswein et al.

Abbreviations: LF-1, limit-feeding, one meal per day; LF-2, limit-feeding, two meals per day; FF, full-feeding; $\mathbf{R F}$, radio frequency; TDA, total duration of daily attendance 


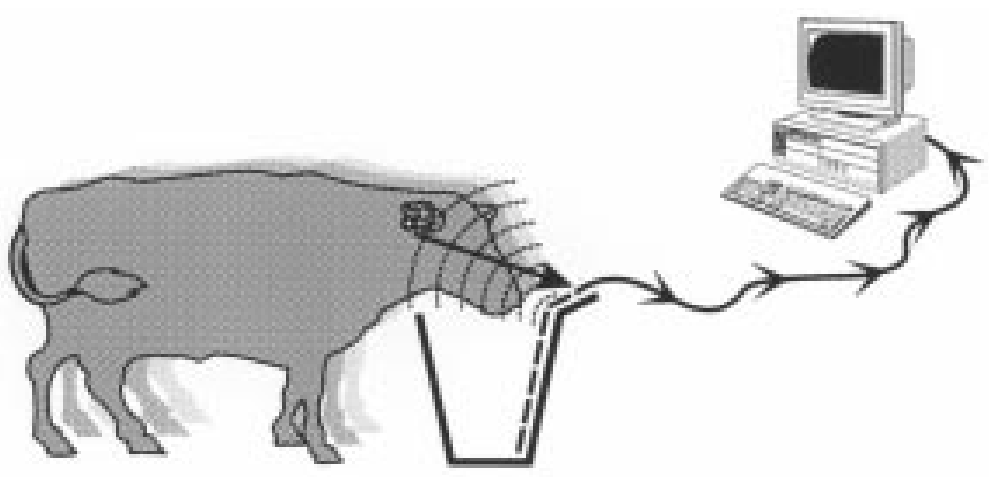

Fig. 1. Schematic diagram illustrating the GrowSafe system.
1998). Correlations between bunk visitation (frequency and duration) and feed intake were also established. Collected data include the time, duration, and location of each bunk visit for each animal within a pen. In order to isolate distinct feeding events, a visit was defined as a return to the feed bunk after an absence of at least $20 \mathrm{~min}$. A return to the bunk after absence of less than $21 \mathrm{~s}$ was considered to be continuous attendance.

An 86-d feeding trial was conducted to investigate the use of RF technology for monitoring bunk attendance of feedlot cattle and to monitor changes in feeding patterns as influenced by feeding strategy. All animals involved in this study were cared for in accordance with the standards set by the Canadian Council on Animal Care (1993). Seventy-two exotic cross steers (average liveweight $412 \pm 23.6 \mathrm{~kg}$ ) of mixed breeding were blocked by weight, tagged with the electronic ID tags and randomly assigned to the four RFequipped pens (18 steers per pen). The steers were fed a steam-rolled barley grain/barley silage diet with 5\% supplement containing vitamins and supplement as per National Research Council (1996) recommendations. For 15 d, a 55\% concentrate diet (DM basis) was fed, then the diet was stepped-up to a $92 \%$ concentrate finishing diet using three transition diets $(65 \%, 75 \%$ and $85 \%$ concentrate) fed for 3 or $4 \mathrm{~d}$ each. Linear bunk space and pen space available for each steer were $25.4 \mathrm{~cm}$ and $12.6 \mathrm{~m}^{2}$, respectively. Accurate detection of transponders was confirmed prior to the trial by manual placement of individual transponders along the full length of the bunk.

Ad libitum intake was approximated daily for each pen from days 34 to 41 as feed delivered minus orts, estimated the following morning. From day 42 to day 65 , the steers were fed at $95 \%$ of the ad libitum intake calculated over the previous $8 \mathrm{~d}$. The limit-feeding period (LF) was split into two sessions to compare bunk attendance patterns in response to once-daily and twice-daily feeding. On days 42 to 52, the feed was delivered in two equal meals, at 09:00 and 15:00 h daily (LF-2). On days 53 to 65, the steers were fed one meal daily, at approximately 09:00 h (LF-1). In order to compare the effects of limit feeding and full feeding (once daily) on bunk attendance patterns, full-feeding (FF) was resumed for the final $21 \mathrm{~d}$ of the trial, with feed provided in a single meal delivered at approximately 09:00 h.

Aspects of bunk attendance assessed were number of visits per day, total duration of daily attendance (TDA) and day-to-day percentage change in TDA for each steer. For each animal, visits per day, TDA and day-to-day change in TDA were averaged across each feeding period. Analysis of variance was performed on each aspect of bunk attendance using the general linear models procedure of the SAS Institute, Inc. (1990), with variation due to pen, animals within pen, and feeding strategy considered in the statistical model. Where appropriate, linear and quadratic responses were determined using orthogonal polynomials.

Over the entire trial, average feed intake by the steers was $11.5 \pm 1.3 \mathrm{~kg} \mathrm{~d}^{-1}$ (DM basis). Average daily gain was $1.6 \mathrm{~kg}$ $\mathrm{d}^{-1}$, and feed conversion efficiency (feed:gain) was 7.2:1. Ambient temperature throughout the trial (July to September) was moderate, averaging $17.5 \pm 3.8^{\circ} \mathrm{C}$.

During the transition period, TDA $(P<0.001)$ and dayto-day change in TDA $(P<0.01)$ decreased linearly as the amount of barley grain in the diet increased (Table 1). The correlation between average TDA and average DM intake measured for each diet throughout the transition period $\left(R^{2}\right.$ $=0.57$ ) may have been confounded by the effects of different grain levels on eating rates (Putnam et al. 1964). Eating rates may also have been influenced by changes in DM density of the diet as the amount of silage decreased.

The GrowSafe ${ }^{\mathrm{TM}}$ system detected primary periods of bunk attendance in the late morning (08:00 to 12:00 h) and late afternoon (16:00 to 20:00 h) during full feeding, which is consistent with findings reported previously from visual observations (Stricklin 1986). During the FF period, steers spent more time at the feed bunk between 16:00 and 20:00 h than between 08:00 and 12:00 h. The situation was reversed for both LF-1 and LF-2 (Fig. 2). During LF-1, the steers spent more $(P<0.005)$ time at the bunk between 08:00 and 16:00 h, and less $(P<0.001)$ time throughout the rest of the day, than during the FF or LF-2 periods. Dissimilar to the FF and LF-2 periods, a late afternoon increase in bunk attendance was not observed during the LF-1 period. Thus, delivery of a second meal significantly affected feeding behaviour when cattle were limit-fed. In contrast, Stricklin (1986) reported only a minor impact of afternoon feeding on fullfed cattle. This difference was likely due to more aggressive appetites arising from limit-feeding in the present trial.

Steers made $7.6 \%$ more visits to the feed bunk $(P<0.001)$ and spent $10.2 \%$ more time there $(P<0.005)$ during LF-2 than during LF-1 (Table 1). Bunks were often observed to be empty for more than $12 \mathrm{~h}$ per day during LF-1, which would explain the decreased bunk attendance compared to 
Table 1. Effect of diet formulation, frequency of feeding and level of feeding on number and duration of feed bunk visits and on day-to-day variability in bunk attendance by feedlot cattle

\begin{tabular}{|c|c|c|c|c|c|c|c|c|c|c|c|c|c|c|}
\hline & \multicolumn{5}{|c|}{ Ration formulation ( $\%$ concentrate $)^{\mathbf{Z}}$} & \multirow[b]{2}{*}{$\mathrm{L}^{\mathbf{w}}$} & \multicolumn{3}{|c|}{ Feeding frequency ${ }^{\mathbf{y}}$} & \multirow[b]{2}{*}{$P$} & \multicolumn{3}{|c|}{ Feeding level $^{\mathbf{x}}$} & \multirow[b]{2}{*}{$P$} \\
\hline & 55 & 65 & 75 & 85 & 92 & & 1/day & 2/day & SEM & & 95 & 100 & SEM & \\
\hline Feed intake $\left(\mathrm{kg} \mathrm{DM} \mathrm{d}^{-1}\right)$ & 12.7 & 12.4 & 11.2 & 12.4 & 11.5 & 0.01 & & & & & & & & \\
\hline Visits to feed bunk $\left(\mathrm{d}^{-1}\right)^{\mathbf{v}}$ & $\begin{array}{l}8.4 \\
(0.09)\end{array}$ & $\begin{array}{l}8.1 \\
(0.08)\end{array}$ & $\begin{array}{l}7.6 \\
(0.09)\end{array}$ & $\begin{array}{l}8.6 \\
(0.07)\end{array}$ & $\begin{array}{l}7.5 \\
(0.03)\end{array}$ & NS & 6.6 & 7.1 & 0.06 & $* * *$ & 6.6 & 7.6 & 0.07 & $* * *$ \\
\hline $\begin{array}{l}\text { Total daily duration of bunk } \\
\text { attendance }(\min )^{\mathbf{v}}\end{array}$ & $\begin{array}{l}55.6 \\
(0.68)\end{array}$ & $\begin{array}{l}43.0 \\
(0.56)\end{array}$ & $\begin{array}{l}42.5 \\
(0.68)\end{array}$ & $\begin{array}{l}48.3 \\
(0.48)\end{array}$ & $\begin{array}{l}30.0 \\
(0.20)\end{array}$ & 0.001 & 29.4 & 32.4 & 0.68 & $* *$ & 29.4 & 33.6 & 0.63 & $* * *$ \\
\hline $\begin{array}{l}\text { Day-to-day change in duration } \\
\text { of bunk attendance }(\%)^{\mathbf{v}}\end{array}$ & $\begin{array}{l}24.8 \\
(3.81)\end{array}$ & $\begin{array}{l}34.9 \\
(3.12)\end{array}$ & $\begin{array}{l}13.9 \\
(4.67)\end{array}$ & $\begin{array}{l}20.2 \\
(2.70)\end{array}$ & $\begin{array}{l}15.0 \\
(1.10)\end{array}$ & 0.01 & 33.4 & 33.5 & 1.14 & NS & 33.4 & 30.9 & 0.88 & $*$ \\
\hline
\end{tabular}

${ }^{\mathbf{z}}$ For ration formulation data, standard errors are indicated in parentheses beneath the means.

$\mathbf{y}_{\text {Feeding at }} 95 \%$ of ad libitum intake.

x\% of ad libitum intake.

${ }^{\mathbf{w}} \mathrm{L}$, linear effect; NS, not significant $(P>0.05)$

values shown are the averages of observations made of 72 cattle during 10- to 21-d feeding periods. SEM, standard error of the mean.

*, **, *** $P<0.05, P<0.005$ and $P<0.001$, respectively.

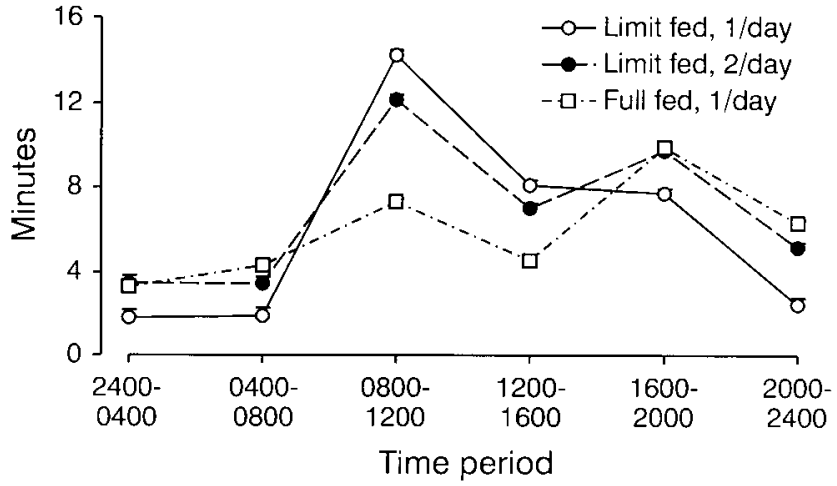

Fig. 2. Average bunk attendance of 72 yearling steers under different feed regimens (LF-1, LF-2 and FF, see text) followed for 13, 10 and $20 \mathrm{~d}$, respectively. Points plotted are averages for 4-h intervals throughout the day.

the LF-2 period, particularly through the night (20:00 to 04:00 h, Fig. 2).

Longer and more frequent bunk visits during LF-2 compared to LF-1 suggests slower average eating rates, given that the same amounts of feed were delivered in these periods. Attendance through the day during LF-2 was more spread out than during LF-1, and closely resembled the attendance observed during the FF period. Goonewardene et al. (1995) suggested little advantage to feeding twice a day when feedlot cattle are provided ad libitum access to barley-based rations, but this increased feeding frequency appears to mitigate competition and spread bunk attendance out over the day when feed is limited. The reduced eating rates and more evenly distributed bunk attendance throughout the day during LF-2 may also have moderated production of acid within the rumen.

Return to a full-feeding strategy following once-daily limit-feeding increased feeding frequency and total bunk attendance $(P<0.001)$ but reduced the amount of day-to- day change in total bunk attendance $(P<0.05$; Table 1$)$. The increased bunk attendance is consistent with the increased intake observed when the steers were given more feed. The reduction in daily change in TDA may be due to reduced competition resulting from continual availability of feed.

Over the course of the trial, TDA for individual steers averaged $33.6 \pm 1.88 \mathrm{~min}^{-1}$, and ranged from 7.7 to $89.2 \mathrm{~min}$ $\mathrm{d}^{-1}$. This average is comparable to that reported by Chirase et al. (1991), but is substantially lower than the $220 \mathrm{~min} \mathrm{~d}^{-1}$ of eating reported for cattle by Chase et al. (1976). However, differences in methodology may have contributed to these differences between studies. Time spent eating is often calculated from time spent standing at the feeder (Putnam et al. 1964; Chase et al. 1976; Keys et al. 1978). In the present study, time spent at the feeder with the head out of the bunk was only considered as feeding time if the animal extended its head back into the bunk within $21 \mathrm{~s}$.

Using surveillance by video camera, Keys et al. (1978) recorded ranges in total daily attendance (measured as time spent at the feeder, irrespective of head placement) at similar bunk space availabilities ( 0.27 to $0.20 \mathrm{~m}$ per animal) from 76.2 to $490.2 \mathrm{~min}^{-1}$ for consumption of a $2.75: 1$ legume silage:concentrate diet. Concentrate or pelleted rations are eaten more quickly by cattle than are forages, and the average intake rates observed in this study $\left(342 \mathrm{~g} \mathrm{~min}^{-1}\right)$ are comparable to those measured for cows by Clough (1972 [quoted by Forbes 1995]) for loose meal (323 $\left.\mathrm{g} \mathrm{min}^{-1}\right)$ and pellets $\left(455 \mathrm{~g} \mathrm{~min}^{-1}\right)$.

The wide range in TDA among steers may reflect differences in eating rates, as much as differences in intake. Although they varied considerably among animals, the TDA values were observed to be quite consistent throughout the trial for each individual and may therefore be useful as an indicator of daily intake by an animal.

Total daily bunk attendance by steers in this study was less than half that observed in commercial feedlots using this same system (Streeter, personal communication). Some of this difference can likely be explained by differences in 
bunk design. Commercial feedyards commonly provide at least $50 \mathrm{~cm}$ of neck space for yearling cattle. By comparison, the neck rails on the bunks in the Lethbridge Research Centre feedlot are low $(82 \mathrm{~cm})$, with only $43 \mathrm{~cm}$ of vertical space for the head and neck to enter the bunk. This limited space may have caused the large yearling cattle to increase in-out head movement, and thus reduce the time that they were detected at the bunk. In a subsequent trial at this facility (data not reported), smaller calves (average body weight $295 \mathrm{~kg}$ ) also averaged over twice as much time at the feed bunk (79.3 min $\mathrm{d}^{-1}$ ) than did the larger cattle used in this trial. This reveals a need to examine the effect of bunk design on bunk attendance.

Day-to-day variation in total feed bunk attendance through the trial ranged from 19.6 to $86.7 \%$, with an average of $28.0 \%$. However, there was no correlation between day-to-day variation and average daily gain. Stock et al. (1995) reported a weak correlation $\left(R^{2}=0.24\right)$ between variation of intake and feed efficiency when a $100 \%$ concentrate diet was fed, but essentially no correlation $\left(R^{2}=\right.$ 0.0009 ) between these factors with a $92.5 \%$ concentrate diet. Although intake variation is a common symptom of subacute acidosis (Larson et al. 1992), all intake variation may not be due to acidosis and therefore, may not necessarily be correlated to performance.

General diurnal patterns of bunk attendance monitored using RF technology were consistent with peak feeding periods reported from visual observation, which supports the accuracy of this observation method. This technology revealed significant changes in bunk attendance related to changes in feeding programs, and it has potential as a valuable tool for assessing a wide range of feeding strategies, including optimal feed delivery programs, feed bunk design and bunk space requirements. By monitoring feeding patterns of individual animals in a pen, RF technology may also indicate occurrence of digestive disturbances, as evidenced by atypical feeding behaviours. The system has been used to determine the relationship between bunk attendance, intake and growth performance (Schwartzkopf-Genswein et al., unpublished data).
The authors gratefully acknowledge the financial assistance of Pfizer Animal Health.

Canadian Council on Animal Care. 1993. Guide to the care and use of experimental animals. Volume 1. E. D. Olfert, B. M Cross, and A. A. McWilliam, eds. CCAC, Ottawa, ON.

Chase, L. E., Wangsness, P. J. and Baumgardt, B. R. 1976. Feeding behavior of steers fed a complete mixed ration. J. Dairy. Sci. 59: 1923-1928.

Chirase, N. K., Hutcheson D. P. and Thompson, G. B. 1991. Effects of monensin on feeding behaviour of feedlot steers and heifers. Beef Cattle Research in Texas. Texas A\&M University, PR 4953: 17-20.

Cole, N. A. 1995. Intake control systems. Pages 156-161 in Symposium: Intake by Feedlot Cattle. OK State Agric. Exp. Sta. P942.

Forbes, J. M. 1995. Feeding behaviour. Pages 11-37 in Voluntary food intake and diet selection in farm animals. CAB International, Wallingford, UK. 532 pp.

Goonewardene, L. A., ZoBell, D. R. and Engstrom, D. F. 1995. Feeding frequency and its effect on feedlot performance in steers. Can. J. Anim. Sci. 75: 255-257.

Keys, J. E., Pearson, R. E. and Thompson, P. D. 1978. Effect of feedbunk stocking density on weight gains and feeding behavior of yearling Holstein heifers. J. Dairy Sci. 61: 448-454.

Larson, E., Stroup, W., Stock, R., Parrott, C., Britton, R. and Laudert, S. 1992. Rumensin/Tylan and feed intake variation. Nebraska Beef Cattle Rep. MP 58: 41.

Putnam, P. A., Lehmann, R. and Davis, R. E. 1964. Rate of feed consumption and body weight of beef cattle. J. Anim. Sci. 23: 425-429.

SAS Institute, Inc. 1990. SAS/STAT user's guide: Statistics, Version 6. SAS Institute, Inc., Cary NC.

Schwartzkopf-Genswein, K. S., Huisma, C. and McAllister, T. A. 1998. Validation of a radio frequency identification system for monitoring the feeding patterns of feedlot cattle. Livest. Prod. Sci. (in press).

Stock, R., Klopfenstein, T. and Shain, D. 1995. Feed intake variation. Pages 56-59 in Symposium: Intake by Feedlot Cattle. OK State Agric. Exp. Sta. P-942.

Stricklin, W. R. 1986. Some factors affecting feeding patterns of beef cattle. In: feed intake by beef cattle. OK State Agric. Exp. Sta. MP 121:314. 